\title{
FRONTIERS
}

\section{Water Woes}

Akissa Bahri

No single magic bullet can solve the developing world's water problems.

N early half of the population of the developing world suffers from diseases associated with the inadequate provision of clean water.

The problem is particularly acute in subSaharan Africa, where there are an estimated 1.2 billion incidences of diarrhoea annually, leading to the deaths of some 770,000 children less than 5 years old.

Little wonder, then, that the provision of clean water is one of the primary focal points of the United Nations Millennium Development Goals (MDGs). The MDGs call for reducing by one-half the number of people worldwide without access to safe drinking water and basic sanitation. The year 1990 serves as the base line and 2015 as the target date.

Providing clean water is first and foremost a public-health issue. Yet there are economic consequences as well. In addition to enjoying a higher quality of life, healthy citizens are more economically productive. Experts estimate that inadequate access to water costs sub-Saharan Africa some US\$23.5 billion a year. That amounts to $5 \%$ of the region's gross domestic product (GDP).

Science and technology (S\&T) plays a vital role in improving access to safe drinking water and developing sustainable approaches for wastewater management. But it is not just S\&T that is important. The social, economic and cultural contexts in which such measures are introduced are equally significant.

Take the case of using wastewater for irrigation, which occurs with great regularity on the urban fringes of virtually all cities in Africa and Asia. Developing-world farmers residing at a city's edge often use untreated or only slightly treated wastewater to grow crops. Researchers estimate that between 4 and 20 million hectares of irrigated agricultural land worldwide (4\% of the world's irrigated farmland) rely on raw, partially treated or diluted wastewater. In sub-Saharan Africa, moreover, urban and peri-urban farmers, who depend on wastewater to grow their crops, produce $70-90 \%$ of the perishable vegetables consumed in African cities.

Wastewater reuse, it is true, has many advantages for farmers and consumers alike. For example, it contains significant nutrients for crop production that not only reduce the need for chemical fertilizers but also increase crop yields. Wastewater, moreover, is potentially a reliable source of water, and using it carries considerable environmental benefits. For example, wastewater reuse offers a low-cost sanitary method of disposal for municipal wastewater, reduces the level of withdrawals from rivers,

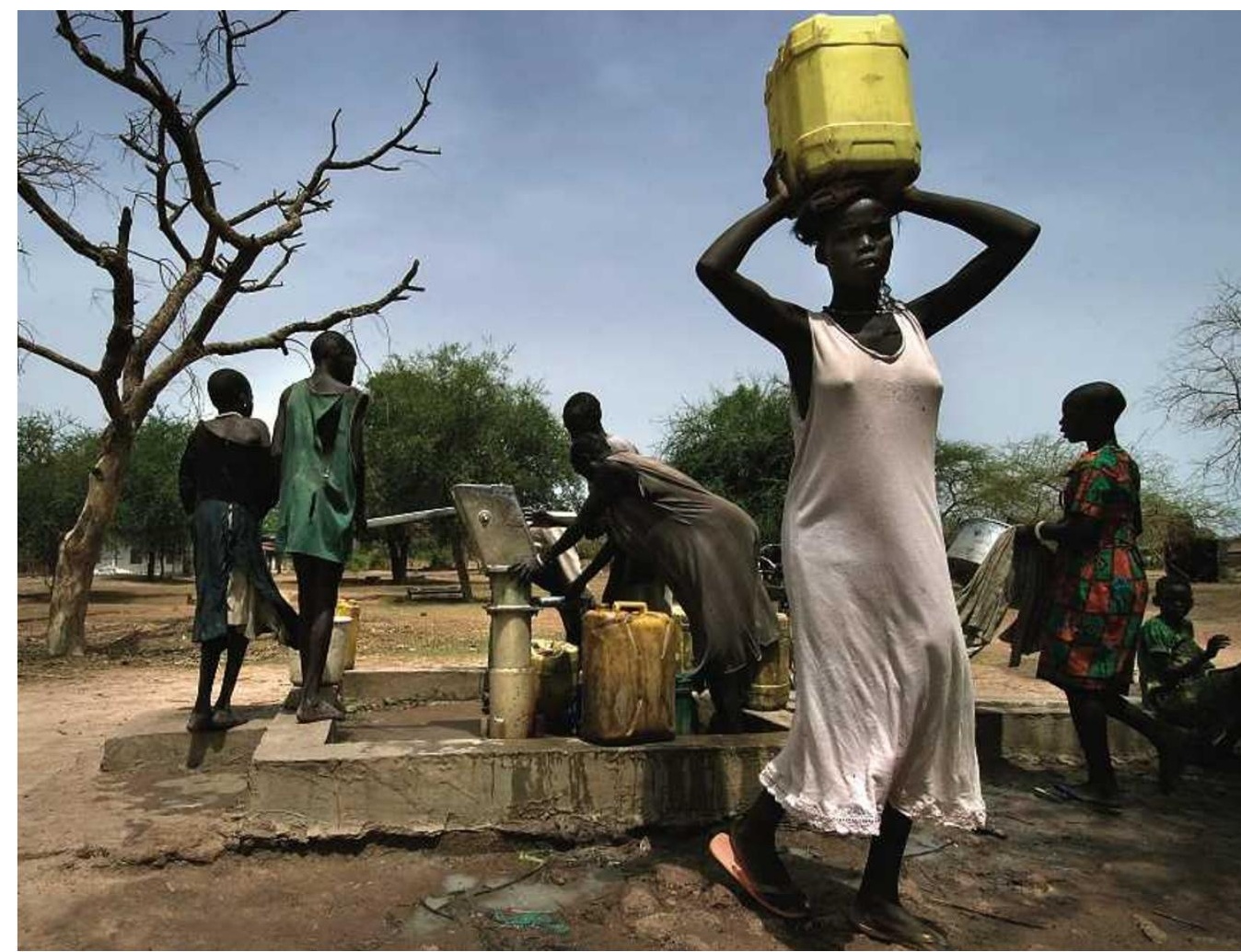

SVEN TORFINN/PANOS

lakes and aquifers, and curbs pollution generated by surface runoff.

Such reuse, however, presents serious potential health and environmental risks that must be addressed. This is where S\&T can play a central role, both by monitoring the nature and extent of the risk, and by providing possible solutions to allow the wastewater to be used safely.

A key challenge, therefore, is to devise safe and effective science-based and technologically sound strategies for reusing wastewater. In Africa, countries such as Tunisia now integrate reuse into the planning and design of wastewater-treatment systems, and Namibia and South Africa have also developed wastewater-treatment and reuse programmes. Yet treatment strategies must still be developed to make wastewater biologically and chemically safe without destroying valuable plant nutrients. Pathogens (bacteria, viruses and parasites) and pollutants (such as cadmium, chromium and lead) must be removed without harming the organisms and minerals in the soil that nourish plants and allow them to grow. Such efforts might help not only to improve public health, but also to raise farm incomes and provide a cleaner environment for all citizens.

Solutions devised in laboratories represent just the initial step in the process. A more critical factor might be the ability to develop decentralized approaches to infrastructure design and development. Local water-treatment plants that can be operated and maintained with the help of the local community would probably prove to be more effective than large, complex watertreatment facilities designed by far-away research institutes or corporations. Water-harvesting practices and more efficient water use would also help. Recycling and reuse, including the measures described earlier for wastewater, would reduce water withdrawals from pristine sources.

Two principles must be kept in mind. First, there is not one solution to the world's water woes; rather, there are many, often small-scale and affordable solutions that, when linked to sustainable agriculture and multiple-use strategies, can make a big difference. Second, S\&T provides major tools for overcoming these problems, but they must be introduced and utilized within a larger policy framework.

Historically, water management and sanitation planning has come from the top down.

End-users have rarely been encouraged to contribute to the process.

Now more than ever, we need planning strategies that unite conventional centralized water-system strategies with efforts made by people at the local level to meet their water and sanitation needs. The provision of environmentally sound systems that take into account the entire water system - supplies, wastewater treatment and reuse, and solid-waste collection - requires a holistic approach that calls for the active participation of all stakeholders.

Adequate water and sanitation systems that meet the needs of the population require good S\&T. Yet, most of all, they require good governance, and a willingness to adopt and adapt good practices from wherever they might originate.

Akissa Bahri (TWAS Fellow 2003) is director for Africa at the International Water Management Institute (IWMI) in Accra, Ghana. 